\title{
ON THE MARKET
}

\section{TISSUE MICROARRAYS}

Ambion's new LandMark neurodegenerative and neuropsychiatric tissue microarrays (TMAs) are designed to make high-throughput analysis possible in highly characterized tissue samples. Each LandMark TMA contains 50 tissue specimens arrayed on a single slide. The expression profile of a specific target can be analyzed across various normal and diseased tissues in a single experiment, providing savings in time, labor and materials, says Ambion.

Tel. (+1) 512-651-0200

www.ambion.com

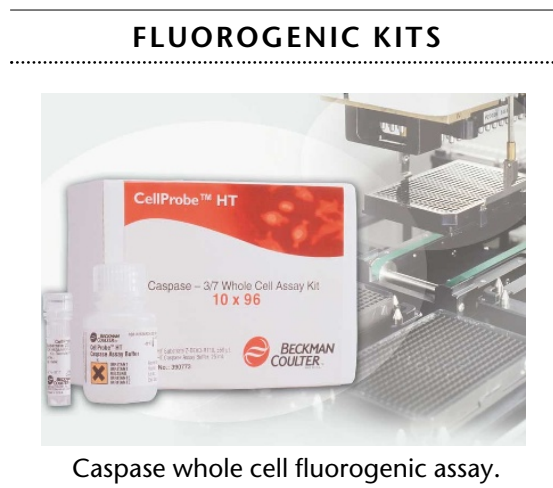

Beckman Coulter introduces a new line of high-throughput fluorogenic kits for cell-based assays. The first of these kits, the CellProbe HT Caspase 3/7 Whole Cell Assay Kit, enables apoptosis detection, an important assay in the development of therapeutics. CellProbe HT assays are whole cellbased and can be automated on Biomek liquid handling workstations. The automation of caspase assays makes it feasible to use them in high-throughput drug discovery applications, such as primary and secondary screening, delivering important information to researchers earlier in the drug discovery process, says Beckman Coulter. The microtiter plate assay kits are available with protocols for 96- and 384-well assay formats. Based on whole cell detection technology, the new CellProbe plate-based assay kits require no protease inhibitors or mixing. By eliminating cell lysis and washing steps, the kits streamline liquid handling for easy automation. CellProbe HT's high specificity enables researchers to easily measure activity in whole cells for de- tection of small changes in enzyme activity.

Tel. (+1) 714-871-4848

www.beckmancoulter.com

\section{STEREOTAXIS}

Stoelting's Lab Standard stereotaxic instrument is intended for stereotaxic procedures with small animals. The ' $U$ ' frame is mounted to a stable 10 $\mathrm{x}$ 14-inch steel base plate. A universal joint manipulator arm mount allows changing the angle of the probe up to $90^{\circ}$ in either the antero-posterior or medio-lateral planes. The manipulator arm facilitates positioning of a pipette or electrode with $80 \mathrm{~mm}$ of vertical, lateral and A-P movement. Moreover, triple-lead screws permit fast positioning, and brass bushings in the manipulator arm allow for electrical grounding. Included is a rat adapter, with $30 \mathrm{~mm}$ of vertical travel along a dovetail slide, and ear bars, which are tapered $18^{\circ}$ at the tip. Non-puncture ear bars are available, as well as species adaptors, to fit mouse, cat, dog, monkey, guinea pig and small bird.

Tel. (+1) 630-860-9700 www.stoeltingco.com

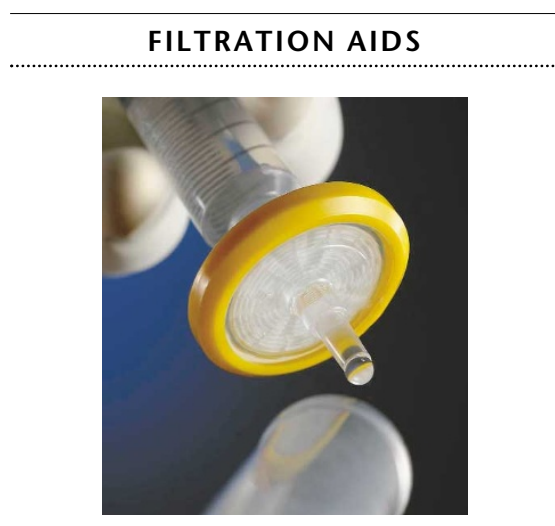

Syringe filter with PVDF membrane.

Millipore announces a new 33-mm Millex syringe filter with Durapore PVDF (polyvinylidene fluoride) membrane, the lowest protein-binding membrane available. The filter is optimal for the sterile filtration of antibiotics, media preservatives and protein-containing solutions. The company says this new generation of Millex filters is $33 \mathrm{~mm}$ in diameter and offers nearly 20 percent more surface area than traditional $25-\mathrm{mm}$ syringe filters. The expanded surface area increases the flow rate and throughput and accelerates filtration. In addition, this advanced Millex filter has a maximum housing pressure of 150 psig (10 bar), allowing users to speed the overall filtration process. Millex filter units with Durapore PVDF membrane are available in 50 and 250 packs with pore sizes of $0.1,0.22$ and $0.45 \mu \mathrm{m}$. Millex filters with $33 \mathrm{~mm}$ diameter are also available with PES (polyethersulfone) and mixed esters of cellulose membrane for general laboratory filtration

Tel. (+1) 800-MILLIPORE

www.millipore.com

\section{PAIN RESEARCH}

Sigma-RBI now offers the potent and selective vanilloid receptor-1 (VR1) antagonist, which should be of interest to those researchers investigating the function of this receptor and its role in pain sensation. VR1 may play a role in the sensation and transduction of signals in response to noxious heat, low $\mathrm{pH}$ and plant irritants. The VR1 antagonist has been shown to inhibit increases in cytoplasmic calcium concentrations in a stable hVR1-expressing cell line induced by capsaicin. It has also been shown to inhibit the activation of hVR1 by several agonists, including temperature, $\mathrm{pH}$, anandamide and eicosanoids.

Tel. (+1) 314-771-5765

www.sigma-aldrich.com

IMPROVING YOUR IMAGE

Leica's new S8 APO Greenough-style stereomicroscope offers a fully apochromatic corrected optics system. When coupled with the Leica 300 digital camera, this stereomicroscope forms a complete digital imaging station. Key features of the S8 APO include an 8:1 apochromatic corrected zoom system that can yield 600 line pairs/mm resolution and modular system options such as supplemental objectives that produce magnifications of $\times 3.2$ to $\mathrm{x} 640$. There is also a built-in photo port for easy adaptation to any digital camera. The microscope also offers a standard working distance of $75 \mathrm{~mm}$ and adjustable upper and lower zoom magnification stops for repeatability at required magnifications.

Tel. (+1) 847-405-0123

www.leica-microsystems.com 